\begin{tabular}{|c|c|}
\hline \multirow{3}{*}{ 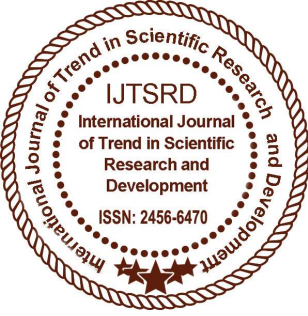 } & $\begin{array}{l}\text { International Journal of Trend in Scientific } \\
\text { Research and Development (IJTSRD) }\end{array}$ \\
\hline & International Open Access Journal \\
\hline & ISSN No: 2456 - 6470 | www.ijtsrd.com | Volume - 2 | Issue - 4 \\
\hline
\end{tabular}

\title{
Corrosion Characterization of Aluminium 6061/ Tib2 Metal Matrix Composites in Sodium Hydroxide Medium
}

\author{
V. Latha \\ Research Scholar, Dept of Chemistry, Bharathiar \\ University, Coimbatore, India
}

\author{
Dr. P. V. Krupakara \\ Vice Principal, Adarsha Institute of Technology, \\ Bangalore, India
}

R. Lakshmi

Professor and Head, Dept of Chemistry, T. John Institute of Technology, Bangalore, India
Department of Chemistry, T. John Institute of Technology, Bangalore, India

\section{ABSTRACT}

This paper deals with the high corrosion resistance developed by the metal matrix composites when compared with that of matrix alloy. Matrix selected is Al6061 and reinforcement selected is TiB2 particulates, which is a ceramic material. The liquid melt metallurgy technique is used to prepare composites. Preheated but uncoated TiB2 particulates are added to the melt. By adding degasifying tablets, the melt is stirred well. Metal matrix composites containing 2, 4 and 6 weight percentage of TiB2 are prepared. Bar castings were taken and are cut into cylindrical discs of $20 \mathrm{~mm}$ diameter and $20 \mathrm{~mm}$ thickness. Corrosion tests were conducted at room temperature $[230 \mathrm{C}]$ using conventional weight loss method according to ASTM G69-80. Different concentrated sodium hydroxide solutions are used as corrodents. Weighed specimens dipped in corrodent solutions and were taken out at every 24 hours of interval up to 96 hours. Four specimens for each condition and time were used and taken out at every 24 hours of interval. Corrosion rates were calculated using the formula 534DAT/W. In all concentrations of sodium hydroxide solutions, corrosion rate decreases with increase in exposure time for matrix and metal matrix composites. As TiB2 content increases the composites become more corrosion resistant due to insulating nature of ceramic material and less exposure of matrix alloy in those metal matrix composites.
Keywords: Composites, vortex, particulates, TiB2, corrodent

\section{INTRODUCTION}

The macroscopic combination of two or more distinct constituents is known as composite. These constituents are essentially insoluble in each other having a recognizable interface between them.

Composites are tailor made constituents to suit particular requirements like reduction in density or improvement in stiffness, yield strength, ultimate tensile strength and wear resistance.

The attractive physical and mechanical properties such as high specific modulus, strength and thermal stability can be obtained from MMCs. Thus, MMCs combine metallic properties with ceramic properties leading to greater strength in shear and compression and higher service temperature capabilities [1-8].

Interest in MMCs for aerospace, automobile and other structural applications has increased over the last few years as a result of the availability of reinforcements and the development of various processing routes which result in reproducible micro structure and properties [9-10].

The trend is now towards the safe usage of the MMCs as components in the automobile engine, at high 
temperature and pressure environments. Typical examples are piston, cylinder liner, brake caliper etc.[11-14].

Over the last two decades, metal matrix composites are of particular interest and the most popular families being represented by aluminum reinforced with ceramic particulates. Many researchers have carried out research work with aluminium 6061 as matrix and used many reinforcements like alumina, silicon carbide, quartz, albite and garnet particulates. But the studies were limited to mechanical properties only. Works related to corrosion studies are very less. The work with red mud as reinforcement for aluminum7075matrix has been carried out by researchers with respect to mechanical properties only.

\section{EXPERIMENTAL PROCEDURE}

\section{A. Material Selection}

In the present study the matrix alloy used is Al6061. The chemical compositions of the Al6061 alloy are given in Table I.

Table I: Composition of Al6061
\begin{tabular}{|l|l|}
\hline Element & $\begin{array}{c}\text { Weight in } \\
\%\end{array}$ \\
\hline $\mathrm{Mg}$ & $0.8-1.5$ \\
\hline $\mathrm{Si}$ & $10-12$ \\
\hline $\mathrm{Fe}$ & 1 \\
\hline $\mathrm{CU}$ & $0.7-1.5$ \\
\hline $\mathrm{Ti}$ & 0.2 \\
\hline $\mathrm{Pb}$ & 0.1 \\
\hline $\mathrm{Zn}$ & 0.5 \\
\hline $\mathrm{Mn}$ & 0.5 \\
\hline $\mathrm{Sn}$ & 0.1 \\
\hline $\mathrm{Ni}$ & 1.5 \\
\hline $\mathrm{Al}$ & $\mathrm{Bal}$ \\
\hline
\end{tabular}

The reinforcement used is $\mathrm{TiB}_{2}$ particulates. It is available commercially. $50-80 \mu \mathrm{m}$ size particulates of $\mathrm{TiB}_{2}$ are used in this study.

The corrosion mediums used to characterize the composites are $0.25 \mathrm{M}, 0.5 \mathrm{M}$ and $1 \mathrm{M}$ solutions of sodium hydroxide.

\section{B. Composite preparation}

Composites are prepared by liquid melt metallurgy technique using vortex method. This method employed by many researchers because of its simple procedure. $\left[{ }^{15]}\right.$ The matrix material Aluminium6061 is heated to its melting temperature and a vortex is created by introducing an impeller made of stainless steel stirrer coated with aluminite (to prevent migration of ferrous ions from the stirrer material to the molten aluminium 6061 alloy). The stirrer was rotated at a speed of $450 \mathrm{rpm}$ in order to create the necessary vortex. Uncoated $\mathrm{TiB}_{2}$ particulates of size $50-80 \mu \mathrm{m}$ was pre heated to $400^{\circ} \mathrm{C}$ in a muffle furnace and added in to the vortex of liquid melt at a rate of $100 \mathrm{~g} / \mathrm{m}$. The composite melt was thoroughly stirred and immediately degasification was carried out by the addition of degasifying tablets made up of hexachloro ethane to the melt. Castings were taken in pre heated permanent moulds made up of cast iron in the form of cylindrical rods with dimensions 30 mmdiameter and length $150 \mathrm{~mm}$. The material was cut into $20 \times 20 \mathrm{~mm}$ pieces using an abrasive cutting wheel. The matrix alloy was also casted under identical conditions for comparison. In this way Aluminium6061 matrix containing 2, 4 and 6 weight percent of $\mathrm{TiB}_{2}$ particulates were produced.

\section{Specimen preparation}

The cylindrical specimen samples with dimension $20 \mathrm{~mm}$ diameter and $20 \mathrm{~mm}$ length were subjected to abrasion using 240, 320, 400 and $600 \mathrm{SiC}$ paper and were polished according to standard metallographic techniques and dipped in acetone and dried. Scanning electron microscope was used to take out the microstructures of the specimens including matrix alloy. The weight of the samples was determined using electronic balance. Weight up to fourth decimal place was noted for all the specimens. The dimensions of the specimen were determined using slide callipers.

\section{Corrosion Test}

The static weight loss corrosion behavior of Aluminum 6061 alloy was carried out by immersing the specimens in the test solutions. For the weight loss test the quantity of corrosion medium solution taken was $200 \mathrm{~cm} 3$. The specimens were immersed for time intervals up to 96 hours in steps of 24 hours. After the specified time the samples were taken out and subjected to mechanical cleanliness by using a brush such that the heavy corrosion deposits on the surfaceis removed. Then specimens are washed with distilled water and acetone and subjected to air drying. Then the weight of the specimens after corrosion testwas determined up to fourth decimal place using the same electronic balance which was used in the beginning. The difference in weights for all the specimens in all the mediums of sodium chloride and sodium 
Hydroxide were determined. Corrosion rates were calculated using the equationCorrosion rate $=534$ W/DAT mpy. Where $\mathrm{W}$ is the weight loss in gm, D is density of the specimen in $\mathrm{gm} / \mathrm{cc}$, A is the area of the specimen (inch) and $\mathrm{T}$ is the exposure time in hours.

\section{III.RESULTS AND DISCUSSION}

\section{A. Microscopy}

Figures 1 to 4 show the microstructures of aluminium 6061 alloy and its $\mathrm{TiB}_{2}$ composites taken using scanning electron microscope. Uniform distribution of $\mathrm{TiB}_{2}$ particulates is observed in composites.

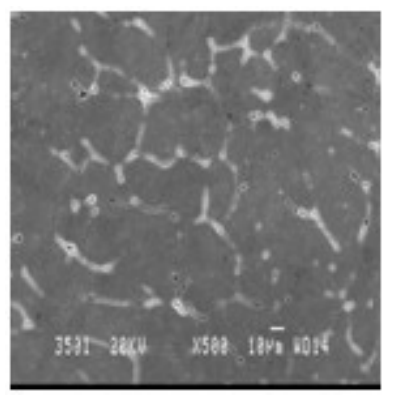

Fig 1: SEM of alloy

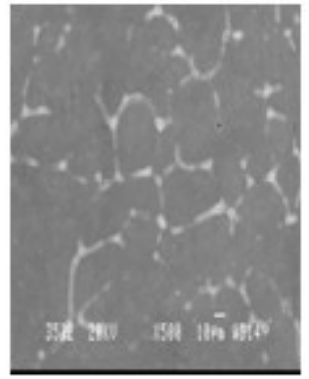

Fig 2: SEM of $2 \%$ MMC

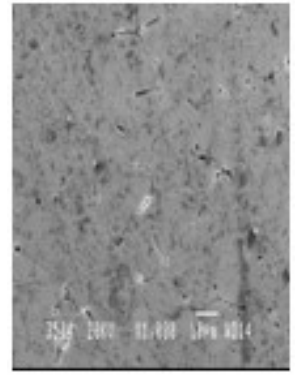

Fig 3:SEM of 4\% MMC

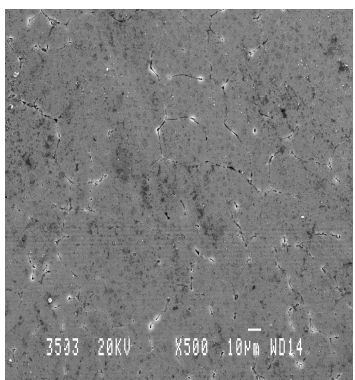

Fig 4: SEM of $6 \% M M C$
Figures 5 to 7 are the graphs plotted by computer simulation in MS excel by taking time of exposure on $\mathrm{x}$ axis and corrosion rate on the $\mathrm{y}$ axis after the corrosion tests in different concentrations of sodium hydroxide.

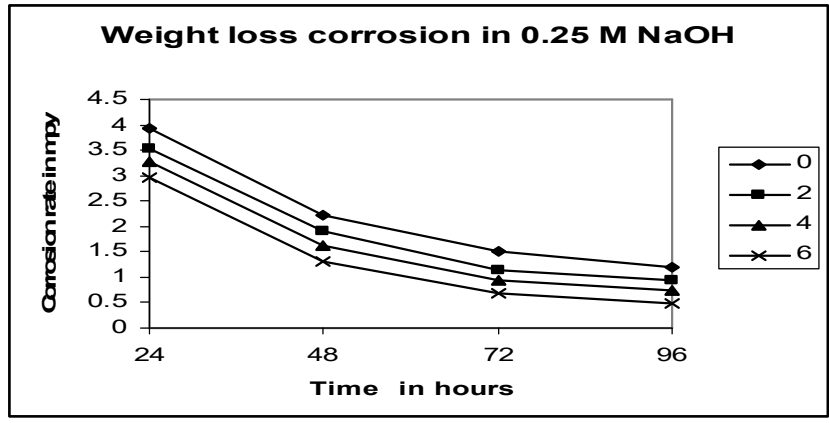

Fig5: Results in 0.25 M NaOH

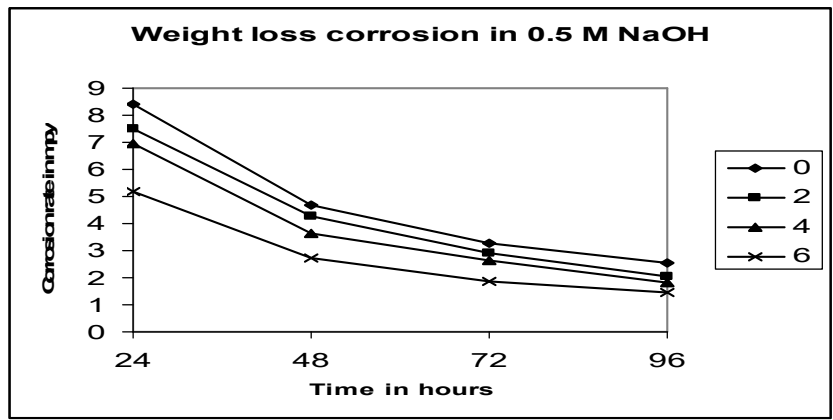

Fig6: Results in $0.5 \mathrm{M} \mathrm{NaOH}$

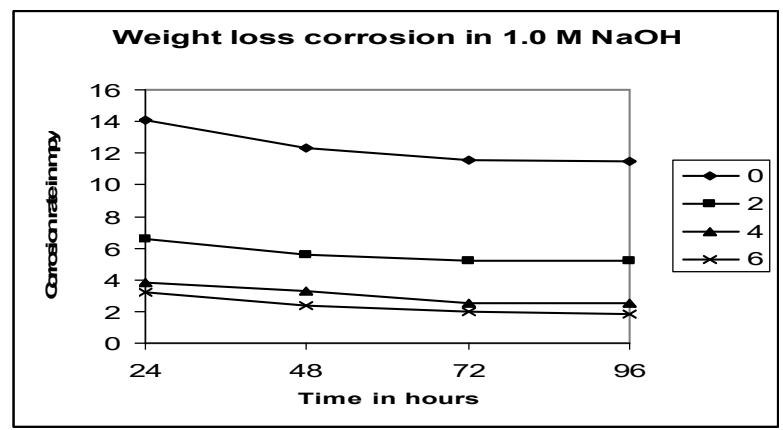

Fig7: Results in $1 \mathrm{M} \mathrm{NaOH}$

\section{B. Effect of exposure time}

From the graphs it's clear that the corrosion rate is found to decrease during the exposure time. The decrease in corrosion rate is due to passivity of the matrix alloy. Visual inspection of the specimens after the corrosion tests revealed the presence of a black film, the composition of black film is $\mathrm{Al}(\mathrm{OH})_{3}$, which covered the surface. Thus $\mathrm{Al}(\mathrm{OH})_{3}$ acts as a passive layer. Since the passive layer acts as a barrier between the fresh metal surface and the corrosive media, it avoids the direct contact between the specimen and the corrosive media, thus further dissolution of the metal alloy would not take place. Corrosion rate depends on the stability, nature and thickness of the 
passive layer. After a specific duration, the film may be stable but it contains porosities and micro cracks through which solution may come in contact with the specimen surface and hence oxygen drifting might take place through these defects in the passive layer. Such passive layer reduces the contact between the specimen surface and corrosion media. Hence it leads to drastic reduction in corrosion rate. During weight loss corrosion test, decrease in corrosion rate with time is due to an increase in the quantity of dissolved $\mathrm{Al}^{3+}$ ions, which leads to the increase in the release of $\mathrm{H}_{2}(\mathrm{~g})$. Hence, the $\mathrm{pH}$ of solution increases. The $\mathrm{H}_{2}(\mathrm{~g})$ evolved also remains entrapped in the crevices or cavities. Thus, it protects these regions from further corrosion. Due to the saturation of the solution with the anodic ions, the anodic reaction is slowed down.

According to Trzaskoma $\left[{ }^{16]}\right.$ if specimen is exposed to saturated media at very high temperature and for a long time, the corrosive chemical reaction would be stopped due to exhaust of conducting media.

\section{Effect of reinforcement}

From the graphs, it is clearly observed that, as the percentage of reinforcement increases rate of corrosion decreases monotonically. This decrease in the corrosion resistance of the composites is explained on the basis of the presence of interface between $\mathrm{TiB}_{2}$ and the Aluminium matrix, which has generated during casting. The presence of a more conductive phase at the interface provides an easier path for the electron exchange necessary for oxygen reduction and will drive the anodic reaction to higher level. The results obtained show that, for both reinforced composite as well as the unreinforced matrix alloy, the corrosion loss seems to decrease with duration of the corrosion test. The phenomenon of gradually decreasing corrosion loss is probably due to protective layer formed, which is quite stable in neutral and many acid solutions but is attacked by alkalis [ ${ }^{18}$ ]

\section{CONCLUSIONS}

Metal matrix composites of Aluminium 6061 and $\mathrm{TiB}_{2}$ reinforcement were manufactured by liquid melt metallurgy technique.

$>$ Microstructures of composites showed uniform distribution of reinforcement.

$>$ In all concentrations of sodium chloride and sodium hydroxide corrosion rate decreased with increase in exposure time.
As the reinforcement content increased in the matrix corrosion rate decreased irrespective of corrosion medium.

\section{APPLICATIONS}

$>$ Al6061 is used as a construction material, most commonly in the manufacture of aircraft and automotive components.

$>$ The Al 6061 is well-suited to the construction of yachts, scuba tanks motorcycles, bicycle frames, camera lenses, fishing reels, electrical fittings.

$>$ It is used in the manufacture of Al cans and the inside foil wrapper on food containers is often made with 6061 aluminum alloys.

Al6061 are also used in wide-span roof structures for bridge decks and arenas.

\section{REFERENCES}

1. B. M. Venkataraman and G. Sunararajan, "The Sliding wear behaviour of Al-SiC particle composites". Acta mater 44(1996) 451-460

2. Krupakara, P. V., Jayaprakash, H. V. Veeraiah, M. K., Gireesha, C, "Computer Simulations of Galvanic Corrosion Behaviour of Zinc Aluminium Based Composites Reinforced with Red Mud by Potentiodynamic Polarization Techniques Leading to Corrosion Control" Applied Mechanics and Materials 110-116 (2012) 1121-1124

3. Effect of reinforcement particle size on the thermal conductivity of a Engineering 77 (1986) 191.

4. S. K. Varma, S. Andrews and G. Vasquez, "Corrosive wear behavior of 2014 and 6061 aluminum alloy composites", J. of material science and performance, 8, No.1 (1999) 98-102.

5. G. S. Murthy, M. J. Koozak and W. E. Frazier, "High temperature deformation of rapid solidification processed/mechanically alloyed Al--Ti Alloys", Scripta metal 21(1987) 141.

6. Hongbo, and D. Hihara, L. H. "Localized Corrosion Currents and $\mathrm{pH}$ Profile over B4C, SiC, and Reinforced 6092 Aluminum Composites in $0.5 \mathrm{M} \mathrm{Na} \mathrm{SO}_{4}$ Solution," Journal of the Electrochemical Society 4 (2005) 152 .

7. YFlom and R. J. Arsenault "Failure behaviour of particulate-reinforced aluminium alloy composites under uniaxial tension," Mater Sci.Engg38(1986) 31 . 
8. Idem "Review on TiC reinforced steel composites," Mater Sci. Engg. 77 (1986) 191.

9. A. H. H. Howes "Fundamentals of Mass Transfer in Gas Carburizing", J. Met 38 (1986) 28.

10. L.H. Hihara "Corrosion of Metal Matrix Composites," chapter in ASM Handbook 13B:

11. A. MortensenJ. A. Cornie and M. C. Flemingsidid "Fabrication of cast particle-reinforced metals via pressure infiltration”, 40 (1988) 12.

12. V. C. Nardone and K. W. Prew "Aspects of strengthening and hardening in particulate metal matrix components", ScriptaMetall 29 (1986) 43.

13. T. W. Chou, A. Kelly and A. Okura "A fibre coating process for advanced metal-matrix composites", Composites 16 (1986) P 187.

14. E. Koya, Y. Hagiwara, S, Miura, T. Hayashi, T. Fujiwara, and M. Onoda, "Development of Al powder metallurgy Composites of Cylinder liners, MMCs. Library of congress catalog card
No.93-87522,Society of Automotive engines", $\operatorname{lnc}(1994)$ 55-64.

15. P. V. Krupakara, Corrosion Characterization of $\mathrm{Al}$ 6061 / Red Mud metal matrix composites, PortugaliaeElectrochemicaActa, 31(3), (2013), $157-164$

16. Fontana, M.G. Corrosion Engineering, McGraw Hill Book Company Inc., New York, (1987), 28115.

17. Trzaskoma. Localized Corrosion of Metal Matrix Composites. Environmental Effects on Advanced Materials, Ed. By R. H. Jones and R.E Ricker. The Minerals, Metals \& Materials Society. (1991) 249-265.

18. S. EzhilVannan and Paul Vizhian Simson, "Corrosion Behaviour of Short Basalt Fiber Reinforced with Al7075 Metal Matrix Composites in Sodium Chloride Alkaline Medium", J. Chem. Eng. Chem. Res. 1(2), 2014, 122. 